\title{
POTENTIAL OF THE PUBLIC SPACE TO PROMOTE ENVIRONMENTAL BEHAVIOR
}

\author{
MARINA MONTELONGO \& UDO DIETRICH \\ Resource Efficiency in Architecture and Planning (REAP), HafenCity University Hamburg (HCU), Germany
}

\begin{abstract}
It is widely recognized that individual environmental behavior plays an important role in curving climate change but it remains unclear how it could be promoted. This paper studies the potential of the public space enabling action. We use an explanatory social mechanism approach to examine what distinctive features of the public space facilitate the implementation of different strategies aimed at overcoming internal and external factors or barriers hindering action and how they do it. A fictitious intervention serves as an example to explain the link between space and action. Our deep and finedgrained analysis points out that accessibility features of the public space and situational features facilitating its use are preconditions for the implementation of all the revised strategies. Visual accessibility facilitates the implementation of social norm-based interventions involving active participation, creating the conditions for other strategies to work, while physical accessibility represents an opportunity to implement availability-based interventions by providing quickly and easy access to the promoted products and services. Situational features refer to the physical characteristics of the space, influencing the nature and scope of the intervention by determining space and infrastructure constraints. Accessibility and possibilities for use lead to multiple forms of social exchange. All the reviewed strategies deal in one way or another with different forms of communication, positioning information as the strategy with the widest range of action. The public space also facilitates civic-based strategies aimed at increasing the participation of citizens on decision-making at administration level. Finally, priming and salience-based strategies can be used to create full lived-in experiences, reinforcing action through sensation and perception processes. The study shows the potentiality of the public space curving climate change towards more sustainable cities and societies through the implementation of a wide range of interventions aimed at making environmental behavior visible and accessible to all.

Keywords: public space, environmental behavior, behavioural change, participation, communication, sustainable cities.
\end{abstract}

\section{INTRODUCTION}

Limiting the impact of global warming on human and natural systems requires the upscaling and acceleration of ambitious mitigation targets through actions to reduce GHG emissions, thus posing challenges associated with changes in behavior [1]. The still limited and incomplete studies on the effectiveness of interventions involving different types of environmental behavior [2] coupled with the observed differential effect an intervention may have according to the target group [3] and the difficulties faced by practitioners in bringing possibilities for action closer to people, have resulted in little progress towards behavioral changes.

A vast body of literature exploring the drivers of human behavior has identified a significant number of internal factors (e.g. environmental knowledge) and external factors (e.g. availability) promoting or hindering environmental behavior [4]-[6]. According to Steg and Vlek [6], interventions should be tailored to the factors influencing the adoption and maintenance of the targeted behavior in order to achieve the best possible outcomes, but the relative influence of the different factors on individual's decisions in different situations is uncertain since decision-making and behavior are the outcome from multiple motivations. While giving feedback about the performance of others may result in energy 
conservation in a metallurgical company [7] results may be vary depending on the frequency and content of feedback provided to households [3]. In the same way, while it has been found a strong association between environmental attitudes and environmental behaviors in the context of consumption [8], attitudes might not be relevant in the work place [9]. Previous research has reported positive results when combining different strategies to achieve behavior change [3], [4], thus confirming the inconsistency and bias in individuals' decisions and highlighting the need of the use of multiple interventions and strategies towards more effective results in promoting environmental action.

While the discussion thus far has mainly focused on the identification of determinants for action and the effectiveness of specific strategies in specific settings, far too little attention has been paid to study the conditions that facilitate the promotion of environmental action through a wide range of interventions on a large scale. Moreover, how to bring a wide range of possibilities for action closer to people reminds uncovered. In addition, participatory approaches aimed at gaining people's involvement and commitment along with contextual factors influencing environmental behavior need more attention [6]. This article aims to help fill those gaps by inquiring about the implications of the public space on facilitating the adoption of environmental behavior. In doing that we use the mechanisms-based approach [10] that makes it possible to formulate deep explanations of the relationship between features of the public space and behavior.

At the center of our effort is the observation that the public space is the arena that brings people together and makes possible a wide range of activities, thus creating opportunities for the spread of environmental behavior through social contagion. According to Carmona et al. [11], public space refers to the physical space where social activities occur. We study the role of features of the public space facilitating the implementation of different interventions aimed at tackling internal and external factors influencing behavior and the micro-level pathways leading to potential success.

This study seeks to contribute to the literature on behavior change and public space in several ways. First, it shifts the focus from the relative effectiveness of specific strategies addressing specific factors influencing behavior to the conditions that facilitate the implementation of a wide range of interventions, thus increasing the possibilities for action. Second, based on in-depth qualitative analysis, we provide theoretical - practical insights into the link between public space and behavior change. In doing this, we deliver a wide range of possibilities that practitioners can use to bring action closer to people and highlight the role of the public space towards sustainable societies and cities.

The paper provides a brief overview of internal and external factors influencing behavior; reviews the most influential strategies encouraging behavior; presents a set of features of the public space; and analyses how those features facilitate the success of different strategies encouraging environmental behavior. Finally, we draw conclusions and discuss our findings.

\section{FACTORS INFLUENCING ENVIRONMENTAL BEHAVIOR}

One basic distinction can be made between internal and external factors influencing behavior. Internal factors involve individual capabilities [4], motivations [6] and preferences [12]. External factors refer to conditions outside the control of the individual that might facilitate or hinder environmental behavior, the latter understood as behavior that harms the environment as little as possible, or even benefits the environment [6]. Literature dealing with the effective promotion of environmental behavior suggests undertaking specific steps towards success, starting with the identification of behaviors with a significant impact on the environment, and finishing with the assessment of the 
effectiveness of the interventions. That literature has pointed out the importance of the identification and subsequent overcoming of factors or barriers to action as a key step toward success. Greater success in overcoming barriers might be achieved through the design of interventions responding to tailor made strategies tackling the identified barriers [4], [6], [13], [14]. In this line of work, we first present some of the most popular internal and external factors influencing behavior, followed by strategies to cope with them. After that, we present a set of characteristics and diversities of the space necessary to understand its role facilitating the implementation of the different strategies.

\subsection{Internal factors influencing behavior}

Motivation: Refers to the reason and internal stimulus for a behavior, implying motives for it and intensity [5].

Values: The values shape much of the individual intrinsic motivation and can be influenced by different actors, factors, contexts, and past experiences [5].

Attitudes: They refer to the persistent positive or negative feeling about some person, object or issue. Attitudes can be strongly influenced by the associated costs in terms of time, effort, money [5] and benefits [15].

Beliefs: Refers to beliefs about the difficulty of taking certain actions or about the consequences for self, others or the environment [4].

Self-interest: Refers to the expected costs and benefits by performing the behavior [15].

General predisposition: Refers to a person with flexibility in order to perform different environmental behaviors, unlike someone willing to perform only certain behaviors [4].

Environmental knowledge: Implies the familiarity with the environmental problem and its causes [5].

Environmental awareness: Refers to the consciousness of the impact of human behavior in the environment. It deals with the link between knowledge and perception of threats and effects, which in turn shapes individual's beliefs, values and attitudes as a response to emotional reactions like fear, sadness, pain, anger, and guilt [5].

Practical and technical knowledge: Implies to know how to lower the environmental impact [5].

Perceived behavioral control: Refers to the perceived possibility to perform the behavior [15] and the ability to bring change [5].

Personal commitment: Is the communicated willingness to take environmental action [5].

Responsibilities and priorities: Refers to the priority given to the individual's responsibilities, being the own well-being and the well-being of the family the highest priority [5].

Perceived feedback about ecological behavior: Refers to the necessary positive reinforcement in order to continue performing the behavior [5].

Social and cultural factors: Refers to the mutual influence between individuals and the societies in which they live [16].

Habits and inertia: Habits refer to the way behavioral choices are made. They are reconsidered when the context changes significantly [6]. Inertia is rooted on habit, acting just as in the past [17].

Injunctive, personal norms: Injunctive norms involve perceptions of which behaviors are typically approved or disapproved, most individuals doing what they think is socially approved [18]. 
Descriptive norms: They involve perceptions of which behaviors are typically common, most individuals doing what is most popular [18].

\subsection{External factors influencing behavior}

Institutional factors: Includes a large number of governance-related issues facilitating or hindering environmental action like government regulations and policies, monetary incentives, physical infrastructure and available technology [4]. While the impact of attitudes and knowledge on individual behavior is uncertain, they might have great impact on citizenship action supporting institutional change [5].

Economic factors: Refers to rational decisions to maximize utility where certain outcomes might be perceived as losses or as unfair [19].

Availability/supply: Refers to the possibility to access products and services necessary to perform the desired behavior [6].

Convenience: Refers to the degree of difficulty to perform the behavior.

Quality: Refers to standards of quality [12].

External factors like economic considerations are intertwined with internal factors. For instance, when the behavior is very costly, individual motivations are not relevant when making decisions [6]. Behavior is the result of the interaction between internal and external factors, where internal factors might create an initial predisposition to act, but the result might be shaped by external factors [4].

\section{STRATEGIES TO INFLUENCE ENVIRONMENTAL BEHAVIOR}

Once the internal and external factors influencing the desired behavior have been identified, intervention strategies can be developed to address each of them. What follows is a selection of strategies addressing internal and external factors towards behavior change.

Information: According to Stern [20], information is an intervention in the personal domain that can influence individual's basic values, beliefs, attitudes, motives and feelings, where the outcome is the result of the interactive effects of the different interventions. For instance, information about alternatives for action might increase individual's environmental knowledge. New knowledge can result in changes in attitudes, which in turn might influence behavior [6]. The skill to apply that knowledge, might lead to immediate action [21].

Information is likely to be more effective when presented at the point of decision, when it provides feedback about the obtained benefits, when people similar to the target group model the message or when it comes from a trusted source. It is also particularly effective when it is reinforced by requesting public commitment or when it highlights the social support for the behavior and gets the involvement of the people [20]. Tailored information prevents information overload and it might be more effective when addressing the personal situation of the individuals, demonstrating clear results and being aligned with their core values and beliefs [1].

Environmental campaigns might have an identifiable component of persuasion [22]. Persuasive messages are characterized by being specific and concrete, having a core idea, being credible, highlighting the individual ability to perform the behavior and its benefits, conveying the idea that the behavior is something good that everybody does, and creating a vision of a desirable future [23].

Social norms: Individuals tend to do what is socially approved as well as is common or popular. The use of injunctive norms implies to highlight what is typically approved or disapproved, referencing the right thing to do. The use of descriptive norms implies to 
highlight what others typically do. Norm-based interventions might be more effective when the descriptive and injunctive messages are aligned, being the information about what others do the most powerful guiding behavior, increasing its effectiveness by making it salient [18]. Descriptive norms about what others do can be communicated via feedback, visual cues or direct observation.

Commitment: This strategy includes the definition of explicit goals, pledges and promises in order to elicit implementation intention. Asking for written, oral, public or private commitment might encourage action, as individuals are motivated to keep their promises and meet their goals due to social pressure [2], [23]. If participants are enrolled in the desired energy program in situ immediately after making commitment, the result might be even better [2]. Commitments work best if they are meaningful, written, made public, and require some effort, increasing the social pressure to be consistent [23].

Priming and salience: Individuals react to information that is made accessible in their mind via priming and to which their attention is constantly drawn via salience. The salience strategy implies constantly to draw the individual's attention, while priming implies the use of subconscious information and sensory cues. Prompts and reminders about energy conservation placed next to light switches might be effective, while displays highlighting the good quality of foods might prime individuals to buy organic food [2].

Role models/modeling: This strategy implies a careful choice of the person or messenger responsible for encouraging the desired behavior. Information is more effective when the individual suggesting the action is perceived as similar [2].

Availability, quality and convenience: This strategy includes actions aimed at providing easy and fast access to good quality products and services and/or providing the optimal conditions to perform the desired behavior. The intervention might tackle the well-identified barriers of time, effort and costs, but also it might consider efficiency options [13].

\section{THE PUBLIC SPACE}

The concept of public space refers to the sites and settings where public life occurs. It is a neutral arena where all kind of social public activities and events take place. There is therefore a strong relationship between space and society [11]. Public spaces range in form, scale and functions, ranging from squares to street corners [24]. In this section, we introduce a set of features and diversities of the public space necessary to understand its potentiality to facilitate action. This is followed by an in deep analysis that explains how those features facilitate the implementation of different environmental strategies.

Accessibility: The public space is closely associated with accessibility, i.e. the capacity to enter and use a space. According to Carmona et al. [11], at least three forms of accessibility must be considered. First, visual access allows individuals to evaluate the place before they enter it, including the level of comfort, acceptance and safety. Second, symbolic access refers to animate (e.g. particular groups) or inanimate (e.g. particular kinds of shops) cues in the environment that might indicate the type of people that are welcome in that place and/or the kind of activity that is expected to perform, including the ability to pay. Third, physical access refers to the physical availability of a given place to all social groups, including use of the environment, implying that it should be open to the "freely" (responsible freedom) chosen and spontaneous actions of all its users. Physical access also presupposes accessibility in terms of public transport [11]. Inviting and easily accessible public spaces encourage people to move from the private to the public environment [25].

Situational features: Human behavior is situational i.e. it is embedded and shaped by physical, social, cultural and perceptual context. The physical environment influences 
individual's decisions in at least three ways. First, the physical environment determines what individuals can do or do not in strictly practical terms. Second, the physical environment determines the surrounding opportunities available to the individuals. Third, the physical environment influences the likelihood of individual action, where some choices are more likely than others depending on the characteristics of a given setting [11].

Opportunities for exchange: The capacity to enter and use a given public space opens the opportunity for multiple forms of socio-cultural and economic transactions to occur, which are key elements in defining a successful place [26]. Socio-cultural transactions include practices of communication, interaction and intermingling, where the public space can be used as an information stage for social learning and personal development through activities involving leisure, entertainment and gaining information. The public space also can function as a forum for political action and representation, involving activities that account for the existence of a civil society and citizens [11]. According to Arendt's interpretation, it is the polis where citizens could participate freely and equally in debating and resolving issues through grassroots collective actions [27]. Economic interactions might involve consumption practices [11] propelled by a wide offer of activities, products, and services such as street markets, cinemas, restaurants, and cultural animation programs among others [26].

Opportunities for sensory experiences: Public spaces are associated with sense of place and lived-in experiences, i.e. the way individuals experience and perceive places through sensation and perception processes. Sensation refers to all human senses. The vision is the dominant sense, codifying what lies before us and providing more information than the other senses combined. The acoustic experience includes all surrounding life, creating opportunities for emotionally rich experiences and gathering of information [11]. Seeing and hearing other people entails participation in social activities in a very subtle way that can lead to other forms of contact as individuals are inspired to take action by seeing others in action [25]. Depending on the situation, the rest of the senses might enrich the live-in experience, which is codified through perception processes. Perception concerns to the understanding of the live experience. It implies cognitive processes involving the gathering, organizing, keeping and making sense of information; affective processes involving feelings; interpretative processes involving associations between past and present experiences, and evaluative processes defining if something is good, bad, valuable or desirable. Despite perception processes occur at individual level, similarities in socialization and past experience in combination with the present environment might lead to the creation of a collective imagery and common place experience [11].

\section{ANALYSIS}

We use a fictional example to illustrate and explain how the different features of the public space facilitate the implementation of different strategies encouraging action. In line with literature dealing with the effective promotion of environmental behavior, we use an intervention with a significant impact on the environment to perform the analysis. Living car free has been identified as one of the actions with the potential to substantially reduce annual individual emissions [28]. We therefore use fictitious interventions aimed at the promotion of the bike as a means of transport to explore the relationship between public space and environmental action.

Accessibility: A bike workshop consisting of a basic unit where people have access to information and tools to repair bikes could serve as a trigger for action. The opportunity to observe a few individuals repairing bikes in a public space might catch the individual's attention. To catch the eye of individuals is three-fold: to establish visual contact with 
them, to encourage them to get into and to show what others do. Since not every individual might have a broken bike at that time, their immediate involvement can be facilitated by offering the opportunity to rent bikes in the setting, increasing the number of participants and the likelihood for action. Calling for higher participation might send out the message that use and repair of bikes is popular and approved, thus the right thing to do in accordance to social norms - based strategies. Printed or visual information communicating the extensive use of bikes in happy neighborhoods and cities might reinforce the idea that biking is something good that many people do. Additionally, every time that a certain number of bikes is successfully repaired and/or rented, the song of a bird might play, stressing the popularity and acceptance of the action. The presence of a group of people might create baseline conditions for the implementation of other environmental strategies.

When the intervention aims to reach a wide audience, it is important to avoid cues in the environment restricting access. For instance, offering only fancy bikes for rent in a fancy environment, might suggest that both rent and reparation are expensive, inhibiting the participation of low-income sectors. On the contrary, cues in the environment might indicate symbolic access to certain groups when role model-based strategies are used to address a target group. Many steps, inadequate surfaces and/or a lack of easy physical access by public transport may prevent action, as a broken bike is heavy and difficult to transport and it must be fixed as soon as possible.

Along with the opportunity to fix and/or rent a bike, every weekend a green market can be organized where people can find a variety of bike-related products like bicycle lamps, or reflector vests, but also bicycle bells imitating animal sounds and wheel-shaped cookies. To have easy and fast physical access to a wide variety of good and competitively prices products might tackle the external barriers of quality, availability and convenience in terms of time, effort and costs, thus facilitating availability-based strategies. An overview of the linkages between accessibility features and the implementation of different behavior strategies is provided in Table 1.

Situational features: The physical characteristics of the space influence the nature and scope of the intervention by determining space and infrastructure opportunities and constraints. Enough and adequate space for intervention would enable the realization of the planned activities, as the installation of the repair units and information boards while a space that it is very small or flooded with fixed urban furniture might impede or limit the implementation of different strategies. A generous space can stage a wide range of events and/or activities supporting the main intervention like the creation of supportive atmospheres, which in turn open an opportunity for more and major interventions, thus expanding the scope for action and increasing the likelihood for it. For instance, if the physical characteristics of the setting make it possible, the fix and rent bikes offer could be expanded by offering bike taxi services, with the consequent increase of related activities, needs and action, like the organization of more public events or the need of more and higher quality bikes, or bike path expansion (Table 2 ).

Opportunities for exchange: Depending on the physical conditions of the space and particular objectives of the practitioners, different information-based interventions to gain and convey information might be considered. That includes a wide range of leisure, entertainment and cultural activities that take advantage of an individual in a state of openness and rest to promote the use of the bike, like the organization of quiz games, raffles, theatre plays, exhibitions and guided bike tours among others. Many types of information might be involved in the different activities, ranging from general environmental information to detailed information on how to fix a bike, addressing different internal and external factors influencing behavior. For instance, information 


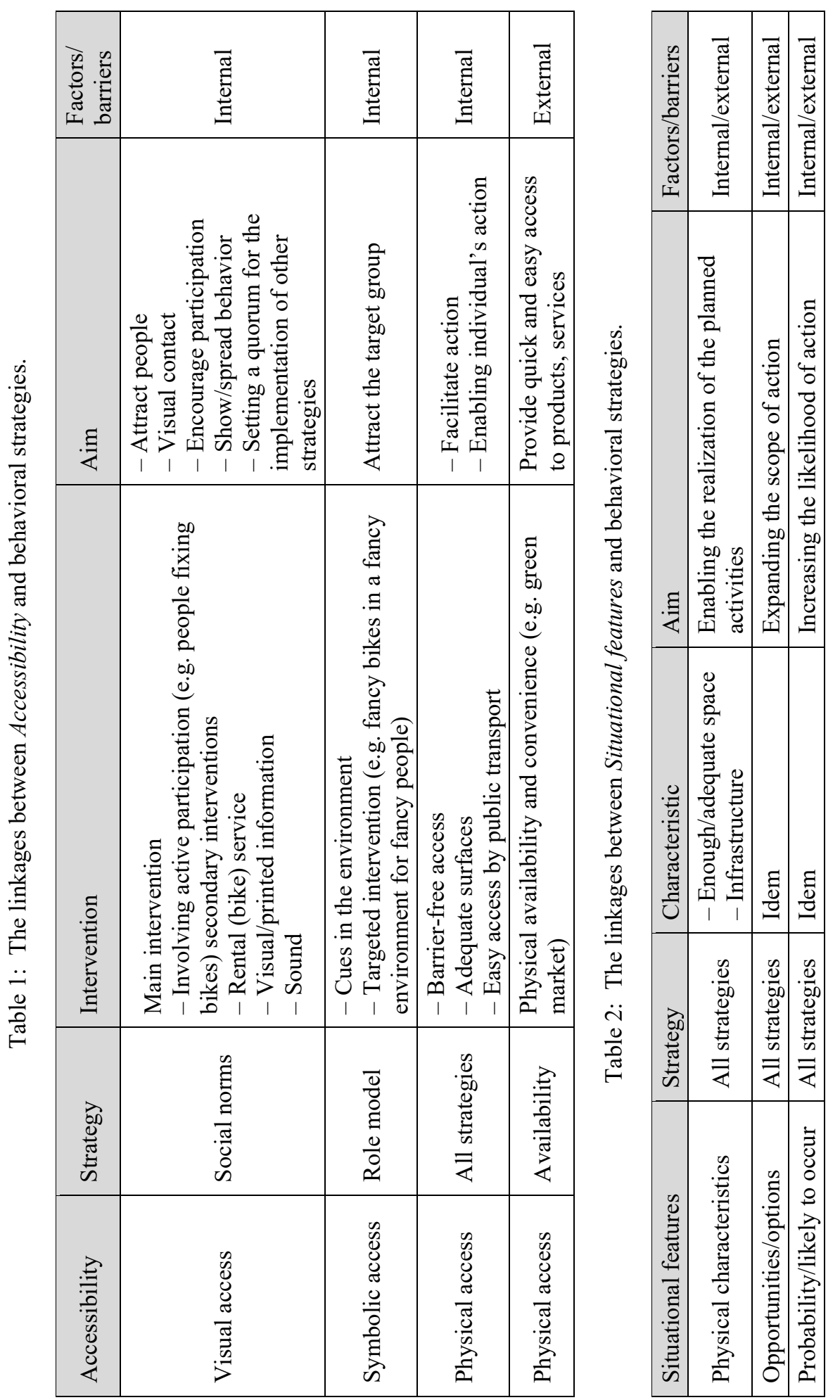


highlighting the social support for the bike elsewhere might encourage the use of the bike through norm compliance, while information about the economic and health benefits of biking might encourage its use through perceived personal benefits. In the same way, information about places where affordable bikes are sold, might overcome inconvenience. Information can be given in different ways, including personal communication, audiovisual material and cues from the environment.

Creating an atmosphere of community through the organization of social events facilitates commitment-based strategies, where individuals might be motivated to make writing, oral or public commitment and to keep their promises as a reaction to the social pressure. Commitments in situ facilitate the performance of the action on different time and space. Some individuals might promise to buy a bike in the green market organized in situ while others pact to participate in the next weekly workshop in order to acquire knowledge on bikes or to save money to buy a bike in the future or to promote the use of the bike at home.

Priming and salience - based strategies placing emphasis on the presentation of options to participants can be used to reinforce success. For example, attractive and visible at eye level to go labels about comparative cost and benefits of different means of transport where the use of the bike is listed at the top, might persuade participants to take action. Salience interventions can include a wide range of types of information that can be conveyed in different ways, including temporary advertising like posters and brochures or through everyday products like T-shirts, caps, cups or pens that the participants can use and hold.

Green markets could support commitment, priming and salience - based strategies by providing the opportunity to take immediate action by acquiring product that facilitate or support the environmental action but also could be used as a framework to implement availability - based strategies. Here, participants might have access to multiple bike-related products, services and barter trade practices, the latter giving participants the opportunity to give a bike helmet in semi-use condition in exchange for bicycle lamps. Depending on the opportunities offered by the physical conditions of the space, different interventions may be designed with the aim to attract different target groups, which in turn might increase the exchange of experiences and enhance the positive effect of the domino effect. For instance, the bike intervention can be complemented by a green food intervention where people can buy on site but food is also distributed by cargo bikes, thus involving new stakeholders like farmers and urban gardeners, who in turn will attract more participants.

Regular organization of events might lead to frequent contact between regular participants in the activities of the place, which in turn might facilitate civic - based strategies involving high levels of organization. Public participation might address institutional factors hindering action. For instance, organized civil society can promote the required funding to encourage mass buying of bicycles, an effective bike-loan system or a plan for the development of cycle paths and pedestrian zones fully integrated with public transport, firmly placing environmental action on the governmental agenda. An overview of the linkages between opportunities for exchange and the implementation of different behavior strategies is provided in Table 3 .

Opportunities for sensory experiences: The status of neutrality of the public space facilitates the openness of the individuals to their surrounding environment. Thus, the creation of a supportive and persuasive ambience for the bike workshop might enrich the live-in experience where the interactive effects of the different interventions will shape individual's decision through sensation and perception processes involving rational and emotional responses as well as value judgements. Sensory experiences might be maximized 


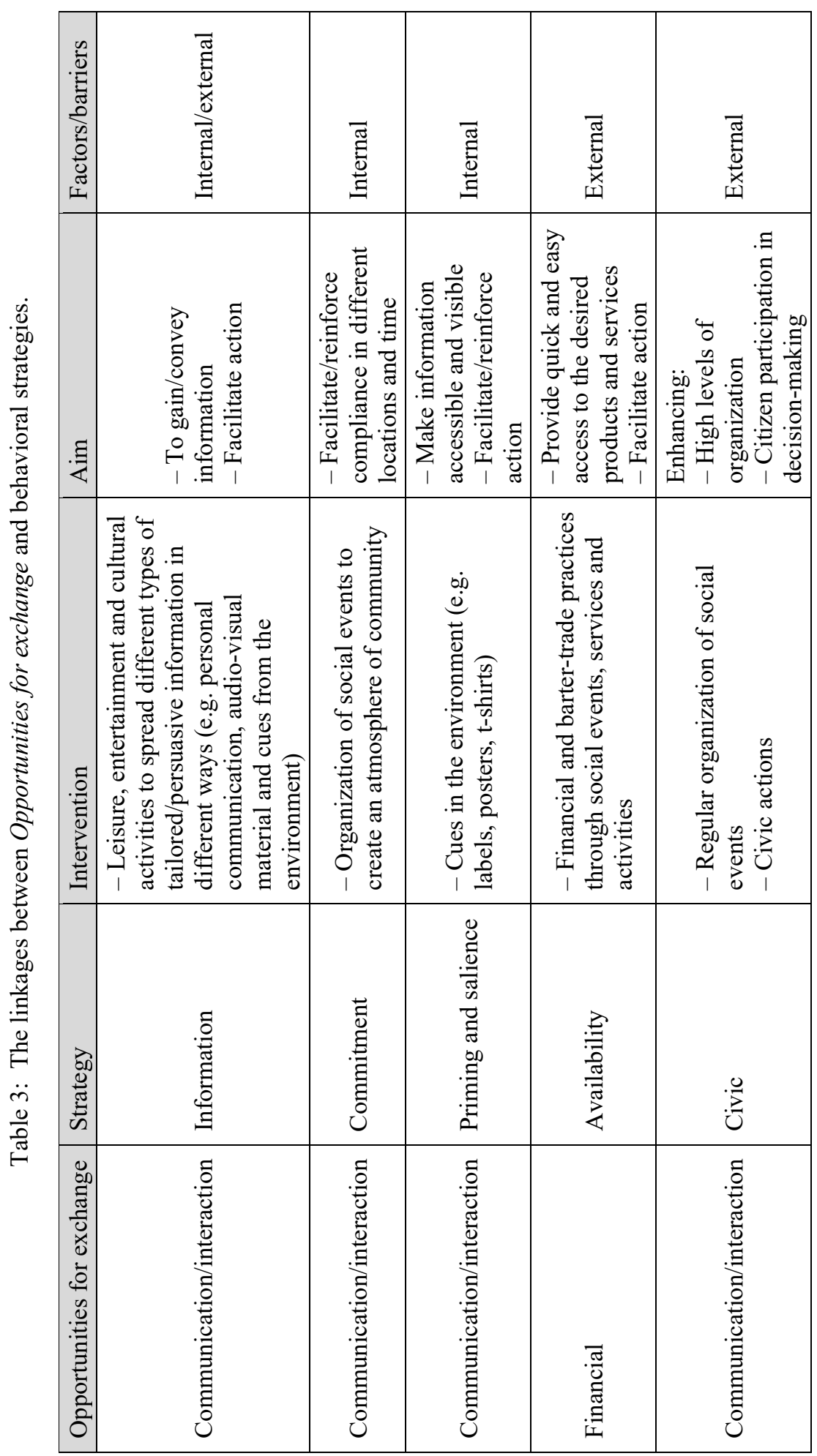




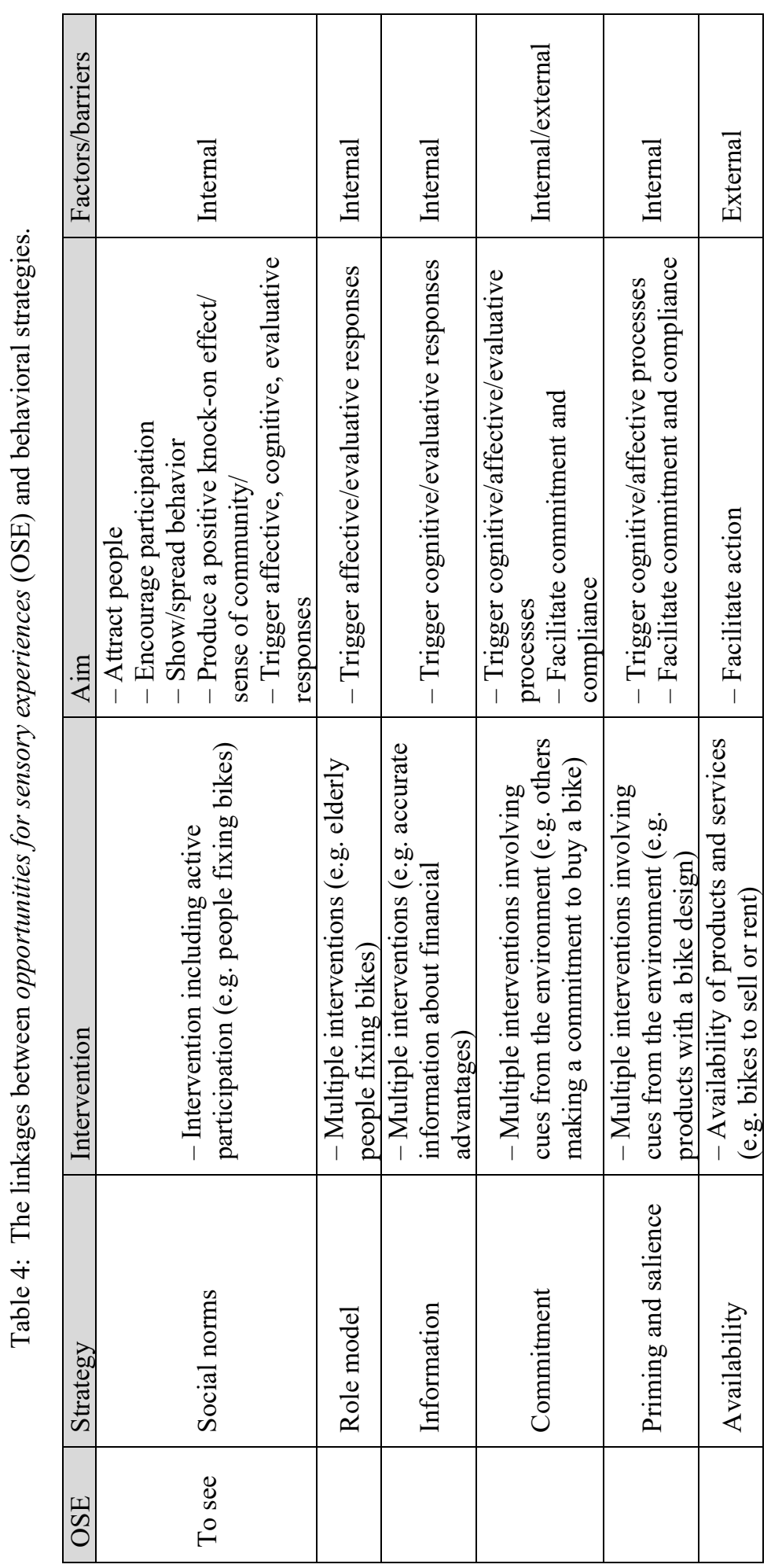


by strategies aimed at the creation of an experience that seduce all the senses. To see people fixing bikes attracts people to the setting, where visual information about the negative effects of the use of cars on elderly and children might elicit a positive emotional response towards action. Accurate information about the financial advantages of biking might facilitate conscious decisions to take action, while cues from the environment in the form of priming, salience and availability-based strategies trigger commitments concerning present and future actions. In the same way, strategies dealing with the other senses might complement the collective place experience. A comprehensive live-in experience might influence both the sense of community and people's sense of well-being when doing the right thing, i.e. well-being by well-doing, which in turn increases the likelihood of individual's action following the social contagion (Table 4).

\section{CONCLUSIONS AND DISCUSSION}

This paper has explained the potential of the public space in promoting environmental behavior. We anticipated that different features and diversities of the public space facilitate the implementation of different strategies aimed at overcoming factors hindering action. Our exploratory analysis provides support for this hypothesis. The first conclusion is that the public space offers ideal conditions for the implementation of all the revised strategies alone or in combination, giving the opportunity for maximizing the effectiveness of public interventions through the combination of strategies. Furthermore, it allows the implementation of strategies aimed at attracting different target groups, thus providing conditions to make environmental behavior visible and accessible to different groups in society.

Second, we found that the implementation of all the reviewed strategies is feasible only when the access to the public space and its use is possible. Accessibility enables individuals to participate actively in different activities. Additionally, it facilitates the spread of different kinds of information. Visual access facilitates the success of social norms-based interventions dealing with activities involving active participation, which can be used as a hook to catch the individual's attention and further involvement. The initial group of people attracted by the ongoing action in the setting might create baselines conditions for the implementation of other strategies. Physical access in terms of public transport creates ideal conditions for the implementation of availability-based strategies by providing quick and easy access to the promoted products and services. A barrier-free design of pavements and infrastructure might support the success of the action by providing easy physical access and mobility in the setting. Just as accessibility is a precondition for each individual participate in the action, the physical conditions of the particular setting enable the realization of the planned activities in practical terms, thus pointing out accessibility features and situational features as preconditions for action. Situational features related to physical conditions of the public space influence the nature and scope of all the included environmental strategies by determining space or infrastructure constraints. A relatively large space allows the implementation of a wide range of strategies and corresponding activities, which in turn have a direct influence on the opportunities for action available to participants and therefore increases the likelihood of action.

Third, all the revised strategies to promote environmental behavior deal in one way or another with different types of information and communication practices, leading to the conclusion that the typical opportunities for exchange condition of public spaces plays a key role spreading action. The following three observations support that assertion: (i) The public space provides ideal conditions to convey information effectively. For instance, the information is presented at the point of decision, trusted sources and specific messengers 
can be used to model the message, it facilitates priming and salience strategies, which in turn facilitates different types of commitment, and it allows multiple possibilities to present accurate, tailored and persuasive information according to the target group. (ii) Different interventions convey a wide range of different types of information, each addressing different factors influencing behavior. For example, information highlighting the social support for the desired behavior encourages action through norm compliance, while information about of the advantages of the behavior encourages action through perceived benefits. (iii) All kind of social events involving leisure, entertainment and cultural activities like theatre plays and exhibitions create conditions for the flowering of multiple forms of communication and interaction, including personal communication, printed and audio-visual material, and cues from the environment. Communication also occurs through events involving financial transactions like green markets. Furthermore, the public space is the arena where advanced forms of communication facilitate civic-based strategies aimed at increasing the participation of citizens in decision-making in environmental matters. Our analysis confirms the relevance of information-based strategies in promoting action and positions information as the strategy with the widest range of applications in the public space.

Another important conclusion is that the public space provides the opportunity to create a persuasive atmosphere that fulfils at least two important functions facilitating action. First, a visually attractive atmosphere can help recruit participants. Here, audio-visual elements can be used to attract the attention from long distances. Second, it supports the success of all the revised interventions by creating an in situ full experience that prompts to action through social contagion but also through sensation and perception processes involving rational and emotional responses. Here, every medium that appeals to the gratification of the human senses can be used to enrich the live-in experience. It is worth noting that priming and salience - based strategies are particularly relevant for creating a persuasive ambience, playing an important role supporting the success of strategies that works with specific groups and targets, like actions involving commitment.

Our study allows for other preliminary observations. It suggests the temporal dimension of the strategies in terms of time and space. For instance, social norms-based strategies making visible that something is popular might encourage immediate action, while taking action may take longer when giving information about how to do something. In the same way, commitment based strategies might encourage action in real time or in the future. These findings call for attention for the action time implications of the different strategies, where immediate action should be priority. Permanence is a different dimension of time, where frequent encounters between people with similar interests or backgrounds might lead to higher levels of citizen participation, which enable citizens to have an impact on decision-making at administration level. To this end, the responsible use of the public space for the better service of citizens must be guaranteed. Using the example of the bicycle workshop, local regulations on the use and activity of the public space might impede or limit the installation of necessary permanent infrastructure for its daily operation and further development. Potential limitations can range from the lack of safe storage areas for tools, the lack of public toilets or restrictions on audio-visual content to a ban of the use of the public space for civic action, highlighting the importance of institutional conditions in facilitating action.

While this work explored socio-functional aspects of the public space, factors typically associated with the architectural and artistic tradition, as spatial arrangements and qualities of the space might also play an important role facilitating action. A place that provides ideal stay conditions in terms of spatial arrangements, urban furniture and aesthetic order calls 
for joint-actions. Here, protection against weather conditions is especially relevant for action, since nobody is supposed to take action under adverse environmental conditions. It is also worth mentioning that interventions aimed at promoting environmental behavior could also serve to meet three of the five needs that people seek to satisfy in a given public space according to Carmona et al. [11], named passive engagement, active engagement and discovery, accompanying the function of providing comfort and relaxation.

The authors want to note that the use of a fictitious intervention to perform the analysis points to an important limitation of this study. Dealing with one fictitious intervention in an undefined location, limits the generalizability of the findings. This however, enabled the authors to carry out an exhaustive analysis of the potentiality of the public space in facilitating very diverse strategies to promote environmental behavior. Future studies might want to focus on real life case studies to understand the unique challenges of each strategy in specific locations, including an effort for understand what represent an adequate space size for the success of the different strategies. Future research also calls for the development of standardized methods to evaluate the combined effect of different strategies on individual's behavior, including the places and times for action.

To conclude, we would like to highlight the potential of the public space to attract and involve a wide diversity of individuals by the use of combined strategies, avoiding the need to be environmental oriented as a precondition to take action.

\section{REFERENCES}

[1] De Coninck, H. et al., Chapter 4: Strengthening and Implementing the Global Response, Intergovernmental Panel on Climate Change (IPCC), 2018.

[2] Byerly, H. et al., Nudging pro-environmental behavior: Evidence and opportunities. Frontiers in Ecology and the Environment, 16(3), pp. 159-168, 2018.

[3] Abrahamse, W., Steg, L., Vlek, C. \& Rothengatter, T., A review of intervention studies aimed at household energy conservation. Journal of Environmental Psychology, 25(3), pp. 273-291, 2005.

[4] Stern, P.C., New environmental theories: Toward a coherent theory of environmentally significant behavior. Journal of Social Issues, 56(3), pp. 407-424, 2000 .

[5] Kollmuss, A. \& Agyeman, J., Mind the gap: Why do people act environmentally and what are the barriers to pro-environmental behavior? Environmental Education Research, 8(3), pp. 239-260, 2002.

[6] Steg, L. \& Vlek, C., Encouraging pro-environmental behaviour: An integrative review and research agenda. Journal of Environmental Psychology, 29(3), pp. 309317, 2009.

[7] Siero, F.W., Bakker, A.B., Dekker, G.B. \& Van Den Burg, M.T., Changing organizational energy consumption behaviour through comparative feedback. Journal of Environmental Psychology, 16(3), pp. 235-246, 1996.

[8] Gadenne, D., Sharma, B., Kerr, D. \& Smith, T., The influence of consumers' environmental beliefs and attitudes on energy saving behaviours. Energy Policy, 39(12), pp. 7684-7694, 2011.

[9] Young, W. et al., Changing behaviour: Successful environmental programmes in the workplace. Business Strategy and the Environment, 24(8), pp. 689-703, 2015.

[10] Hedström, P. \& Swedberg, R., Social mechanisms: An introductory essay. Social Mechanisms: An Analytical Approach to Social Theory, pp. 1-31, 1998.

[11] Carmona, M., Heath, T., Tiesdell, S. \& Oc, T., Public Places, Urban Spaces: The Dimensions of Urban Design, Routledge, 2010. 
[12] Cattaneo, C., Internal and external barriers to energy efficiency: Which role for policy interventions? Energy Efficiency, 12(5), pp. 1293-1311, 2019.

[13] Geller, E.S., The challenge of increasing proenvironmental behavior. Handbook of Environmental Psychology, eds R.B. Bechtel \& A. Churchman, Wiley: New York, pp. 525-540, 2002.

[14] McKenzie-Mohr, D., Fostering Sustainable Behavior: An Introduction to Community-Based Social Marketing, New Society Publishers, 2011.

[15] Lindenberg, S. \& Steg, L., Normative, gain and hedonic goal frames guiding environmental behavior. Journal of Social Issues, 63(1), pp. 117-137, 2007.

[16] Hinde, R.A., Individuals, relationships and culture: Links between ethology and the social sciences. CUP Archive, 1987.

[17] Manolas, E., Promoting pro-environmental behavior: Overcoming barriers. AEJES, 1, pp. 13-21, 2015.

[18] Cialdini, R.B., Crafting normative messages to protect the environment. Current Directions in Psychological Science, 12(4), pp. 105-109, 2003.

[19] Wilson, C. \& Dowlatabadi, H., Models of decision making and residential energy use. Annual Review of Environment and Resources, 32, pp. 169-203, 2007.

[20] Stern, P.C., Information, incentives, and proenvironmental consumer behavior. Journal of Consumer Policy, 22(4), pp. 461-478, 1999.

[21] McKenzie-Mohr, D., Nemiroff, L.S., Beers, L. \& Desmarais, S., Determinants of responsible environmental behavior. Journal of Social Issues, 51(4), pp. 139-156, 1995.

[22] Syme, G.J., Nancarrow, B.E. \& Seligman, C., The evaluation of information campaigns to promote voluntary household water conservation. Evaluation Review, 24(6), pp. 539-578, 2000.

[23] James, R., Promoting sustainable behavior: A guide to successful communication. University of California, Berkeley, Office of Sustainability, 2010.

[24] Carmona, M., Principles for public space design, planning to do better. Urban Design International, 24(1), pp. 47-59, 2019.

[25] Gehl, J., Life Between Buildings: Using Public Space, Island Press, 2011.

[26] Montgomery, J., Making a city: Urbanity, vitality and urban design. Journal of Urban Design, 3(1), pp. 93-116, 1998.

[27] Bokiniec, M., Is polis the answer? Hannah Arendt on democracy. Santalka: Filologija. Edukologija, 17(1), pp. 76-82, 2009.

[28] Wynes, S. \& Nicholas, K.A., The climate mitigation gap: Education and government recommendations miss the most effective individual actions. Environmental Research Letters, 12(7), p. 074024, 2017. 